\title{
Role of pharmacogenomics in the treatment of tuberculosis: a review
}

This article was published in the following Dove Press journal:

Pharmacogenomics and Personalized Medicine

12 September 2012

Number of times this article has been viewed

\section{Geetha Ramachandran Soumya Swaminathan}

National Institute for Research in Tuberculosis, Indian Council of Medical Research, Chennai, India

Correspondence: Soumya Swaminathan Department of Clinical Research, National Institute for Research in Tuberculosis, Mayor VR Ramanathan Road, Chetpet, Chennai 600 03I, India

Tel +9l 4428369586

$\mathrm{Fax}+9 \mid 4428362528$

Email doctorsoumya@yahoo.com
Background: Tuberculosis is one of the major public health problems worldwide. Modern antituberculous treatment can cure most patients; cure rates $>95 \%$ are achieved with standard short-course chemotherapy regimens containing isoniazid, rifampicin, pyrazinamide, and ethambutol among patients with drug-susceptible strains of tuberculosis; however, a small proportion do not respond to treatment or develop serious adverse events. Pharmacogenomic studies of drugs used in the treatment of tuberculosis could help us understand intersubject variations in treatment response. In this review, we compiled pharmacogenomic data on antituberculous drugs that were available from different settings that would give a better insight into the role of pharmacogenomics in the treatment of tuberculosis, thereby enhancing the efficacy and limiting the toxicity of existing antituberculosis medications.

Methods: The PubMed database was searched from 1960 to the present using the keywords "tuberculosis", "antituberculosis treatment", "isoniazid", "rifampicin", "pyrazinamide", "ethambutol", "pharmacogenomics", and "polymorphism". Abstracts from meetings and review articles were included.

Conclusion: Studies conducted in different settings suggest that pharmacogenomics plays a significant role in isoniazid metabolism, and impacts both treatment efficacy and frequency of adverse reactions. Single nucleotide polymorphisms influencing plasma rifampicin concentrations are also reported. No data are available regarding other first-line drugs, ie, ethambutol and pyrazinamide. There is a need to incorporate pharmacogenomics into clinical trials of tuberculosis in order to understand the factors impacting therapeutic success and occurrence of adverse drug effects.

Keywords: tuberculosis, antituberculous treatment, pharmacogenomics, polymorphism, drug metabolism

\section{Introduction}

Tuberculosis continues to remain a major public health problem. One third of the world's total population are infected with Mycobacterium tuberculosis, the organism causative of tuberculosis. One in every 10 infected persons will break down with active tuberculosis during their lifetime. If untreated, each person with active tuberculosis is likely to infect about $10-15$ persons per year, and persons infected with human immunodeficiency virus (HIV) are at higher risk. ${ }^{1}$ Africa, followed by India and China, are among the 15 countries with the highest estimated tuberculosis incidence rates. ${ }^{1}$ Despite the availability of highly efficacious treatment for decades, tuberculosis remains an important cause of death. In 2010, there were 8.8 (8.5-9.2) million incident tuberculosis cases, $1.1(0.9-1.2)$ million tuberculosis deaths among 
HIV-negative subjects, and an additional 0.35 (0.32-0.39) million deaths due to HIV-associated tuberculosis.

Tuberculosis has been treated with combination therapy for over 50 years, following the recognition early on that M. tuberculosis develops resistance rapidly when single drugs are used for treatment. ${ }^{2}$ Treatment of both pulmonary and extrapulmonary tuberculosis is usually for 6 months with isoniazid, rifampicin, pyrazinamide, and ethambutol for 2 months, followed by isoniazid and rifampicin for the following 4 months. This regimen is highly efficacious, with cure rates $>95 \%$ and relapse rates $<5 \%$ in patients with tuberculosis who are not infected by HIV and have drugsusceptible bacilli. ${ }^{3}$ Tuberculosis is treated with combination therapy because $M$. tuberculosis develops resistance rapidly when single drugs are used for treatment. Multiple drug therapy is not only to prevent emergence of drug resistance, but also to treat different populations of tubercle bacilli.

\section{Pharmacogenomics}

Pharmacogenomics is defined as the study of the genetically determined molecular basis of drug treatment outcomes, and has evolved over the past 20 years. Treatment outcomes can be classified into two broad areas, ie, efficacy and toxicity. Interindividual differences in response to the same drugs are known to occur. These differences are higher among individuals belonging to the same population than within the same individual at different times. ${ }^{4}$ Inheritance as a determinant of drug response can be explained by the fact that huge population variations with minimal within-subject variations exist. About $20 \%-95 \%$ of variations in drug pharmacokinetics and effects are estimated to be due to genetic factors, ${ }^{5}$ although there are examples in which interindividual variations in drug response are known to occur due to sequence variants in genes coding for drug-metabolizing enzymes, drug transporters, or targets. ${ }^{6-8}$ Nongenetic factors, such as age, organ function, concomitant therapy, nutritional status, drug interactions, and nature of the disease can also impact drug effects. However, inherited determinants remain constant throughout the lifetime of the individual.

Clinical observations of inherited differences in drug effects were first reported in the 1950s. ${ }^{9-12}$ An important aim of pharmacogenomics is to develop a rational means to optimize drug treatment, thereby ensuring maximum efficacy with minimum toxicity. ${ }^{13}$ The concept of "personalized medicine" holds promise in that drugs and drug combinations are optimized for the genetic makeup of the individual. ${ }^{14,15}$ Pharmacogenomics has wide applications in several diseases, including cancer, cardiovascular disease, depression, bipolar disorder, attention deficit disorder, HIV, tuberculosis, asthma, and diabetes. ${ }^{16}$

\section{Pharmacogenomics and tuberculosis}

Among the several drugs used to treat tuberculosis, pharmacogenomics is known to play an important role in the metabolism of isoniazid, a key first-line drug used to treat tuberculosis. ${ }^{17}$ This in turn could have important clinical implications in terms of therapeutic efficacy ${ }^{18}$ and occurrence of adverse events. ${ }^{19}$ There are a few reports available that suggest a role with respect to rifampicin, ${ }^{20,21}$ while not much information is available regarding genetic differences in the metabolism of other first-line and second-line antituberculous drugs.

While most of the currently available review articles have covered the relationship between pharmacogenomics and isoniazid-induced hepatotoxicity, ${ }^{19,22}$ we have extended the scope of this review to include the effect of genetic polymorphisms on the efficacy of treatment for tuberculosis. Further, we have included available information on rifampicin and aminoglycosides.

\section{Isoniazid}

Ever since its introduction in 1952, isoniazid has been an important drug in the treatment of tuberculosis. It has all the essential properties of an ideal chemotherapeutic agent, ie, it is highly effective, quite specific in its action against the tubercle bacilli, has minimal toxicity, and is not expensive. ${ }^{18}$

\section{Metabolism}

Isoniazid is metabolized by acetylation, which takes place mainly in the liver and gut mucosa. This conjugation reaction is catalyzed by N-acetyl transferase (NAT2) during which an acetyl group from acetyl coenzyme A gets transferred to the acceptor amine, thereby forming an amide. Acetylation of isoniazid results in formation of acetyl isoniazid, which becomes conjugated with pyruvic acid and $\alpha$-ketoglutaric acid to form hydrazones, and acetyl isoniazid becomes hydrolyzed to monoacetyl hydrazine and isonicotinic acid. Monoacetyl hydrazine undergoes acetylation to form diacetyl hydrazine, and isonicotinic acid becomes conjugated with glycine to form isonicotinyl glycine. All the metabolites of isoniazid are devoid of antituberculous activity. A schematic representation of isoniazid metabolism is shown in Figure $1 .{ }^{19}$ 


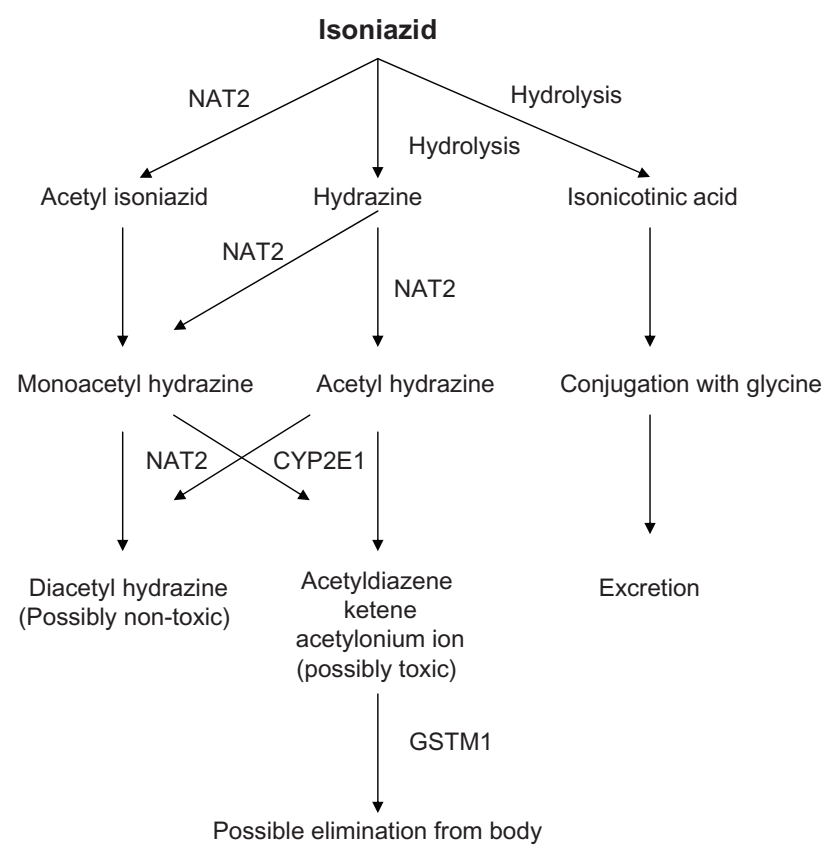

Figure I Suggested metabolic pathways of isoniazid and metabolites via NAT2, CYP2EI, and GSTMI. (C) Copyright Future Medicine. Reprinted with permission from Roy PD, Majumder M, Roy B. Pharmacogenomics of anti-TB drug-related hepatotoxicity. Pharmacogenomics. 2008. ${ }^{19}$

\section{Acetylator genotypes and phenotypes}

The acetylator status of a person is genetically determined, and the rate of acetylation of isoniazid varies from individual to individual due to differences in the concentrations of cytosolic NAT2 enzyme in the liver and gut mucosa. Many commonly prescribed drugs are detoxified by NAT2, which exhibits a high level of polymorphism. Variability in the expression of NAT2 can therefore affect the therapeutic response to drugs. Individuals with reduced NAT2 expression may have different drug levels than those with normal expression. Consequently, such persons may need a different dosage schedule of drugs that are metabolized by NAT2.

The enzyme activity is expressed at highly variable levels. Several studies over the years have shown that human subjects show a wide degree of variation in their capacity to acetylate or inactivate isoniazid to acetyl isoniazid, and they can be distinctly characterized phenotypically as being either slow or rapid inactivators (the concentration of the enzyme being higher in rapid inactivators). Figure 2 shows a bimodal distribution of plasma isoniazid concentrations in slow and rapid acetylators given the same dose of isoniazid. ${ }^{23}$ Molecular techniques that are now available permit identification of three genotypes, ie, rapid, intermediate, and slow.

Wild-type (rapid acetylator) alleles are those in which the $N A T 2 * 4$ allele codes for a completely active enzyme. Rapid acetylators can be administered drugs that are substrates of the NAT2 enzyme according to conventional doses.

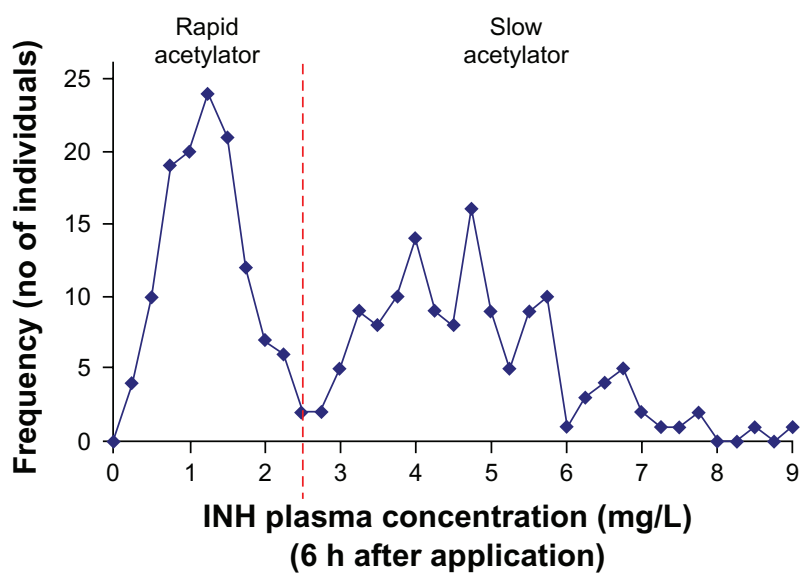

Figure 2 Bimodal variation in isoniazid exposure..$^{23}$

Note: Plasma isoniazid concentrations were determined in subjects at six hours after isoniazid administration.

Abbreviation: $\mathrm{INH}$, isoniazid.

Intermediate acetylators are those with one active and one inactive NAT2 allele (heterozygous). They might require lower than average drug dosages for a favorable therapeutic response. Several mutations in the NAT2 gene account for the majority of the slow acetylator genotypes in the human population $(N A T 2 * 5 A, N A T 2 * 5 B$, and $N A T 2 * 6 A){ }^{24}$ Such individuals are at greater risk of drug-induced adverse reactions due to reduced drug elimination. Acetylator gene frequency for the slow allele differs across ethnic groups and countries, being $10 \%$ in people from the mongoloid races like the Eskimos, Japanese, and Chinese, $90 \%$ in the Middle East, $60 \%$ in the Negroid, Caucasian, and south Indian populations, and $72 \%$ in the US.

A study by Kinzig-Schippers et al in 18 healthy Caucasians showed that NAT2 genotypes accounted for $88 \%$ of variability in apparent isoniazid clearance, while isoniazid preparation and body weight accounted for $2 \%$ and $3 \%$ of variations, respectively. ${ }^{24}$ There exists a linear relationship between isoniazid clearance and number of high-activity NAT2 alleles (Figure 3). ${ }^{25}$ Parkin et al observed variations in isoniazid disposition among subjects with different NAT2 genotypes, slow acetylators having 4-6-fold higher serum isoniazid concentrations. ${ }^{26}$ Based on this study, an individualized isoniazid dosing regimen was suggested. Similarly, a study comparing urinary isoniazid excretion between healthy volunteers and patients showed that subjects with a higher number of active NAT2 alleles had higher levels of isoniazid acetylation. ${ }^{27}$

\section{Isoniazid acetylator status and treatment efficacy}

Scanty information is available on the association between isoniazid blood concentrations, efficacy, and toxicity. Mitchison 


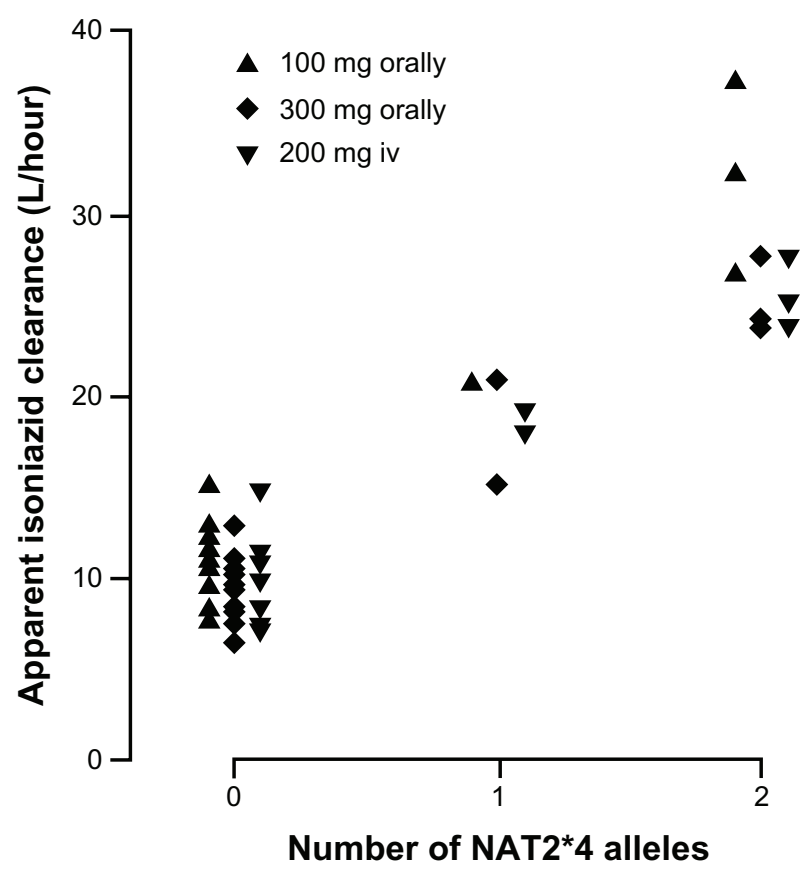

Figure 3 Individual clearance of isoniazid in relation to the number of high-activity NAT2*4 alleles. (C) Copyright American Society for Microbiology. Reprinted with permission from Kinzig-Schippers M, Tomalik-Scharte D, Jetter A, et al. Should we use $\mathrm{N}$-acetyl transferase type 2 genotyping to personalize isoniazid doses? Antimicrob Agents Chemother. 2005;49(5): 1733-1738. ${ }^{25}$

proposed that the peak isoniazid concentration to minimum inhibitory concentration ratio could serve as a predictor of outcomes of tuberculosis treatment. ${ }^{28}$ It has been established that plasma isoniazid levels influence the mean early bactericidal activity of isoniazid, which is lower in rapid acetylators than in slow acetylators. ${ }^{29}$ Therefore, it is possible that low plasma isoniazid levels in rapid acetylators could be one of the causes for occasional therapeutic failure or relapse. ${ }^{30} \mathrm{On}$ the contrary, higher levels in slow acetylators could predispose to toxicity. Thus, NAT2 genotyping prior to isoniazid administration would help clinicians in predicting pharmacokinetic variability, and adjusting isoniazid dose. Isoniazid dosing could be adjusted for subjects with none, one, or two rapid NAT2 alleles to achieve similar isoniazid exposure.

Studies to understand the relationship between isoniazid acetylator status and treatment outcome in patients with pulmonary tuberculosis receiving treatment with isoniazid alone or in combination with p-amino salicylic acid were undertaken. Comparison of response to tuberculosis treatment between slow and rapid inactivators of isoniazid suggested an association between treatment response and rate of inactivation of isoniazid, and there was a difference in the rate of conversion to bacteriological negativity between slow and rapid inactivators. ${ }^{31}$ Under trial conditions, it appears that isoniazid acetylator status has little prognostic significance during daily, twice-weekly, or three times weekly tuberculosis treatment. ${ }^{17,32,33}$ However, in field conditions or in cases of drug irregularity, isoniazid acetylator status may acquire some importance in daily regimens, and may have an appreciable effect on outcomes among patients on three times weekly and twice-weekly regimens. ${ }^{18}$ Controlled clinical trials using once-weekly isoniazid-containing treatment regimens demonstrated that response to treatment was better in slow acetylators compared with rapid acetylators, the differences in cure rate being in the order of $20 \%-35 \%$ $(P<0.001$, Table 1$) .{ }^{34}$ In order to elucidate the reasons for the inferior response of rapid acetylators, studies of serial serum isoniazid concentrations in slow and rapid acetylators were undertaken. Table 2 presents the peak concentration, coverage, and exposure to isoniazid attained at a dose of $15 \mathrm{mg} /$ $\mathrm{kg} .{ }^{18}$ The peak concentration attained in slow acetylators was slightly higher than that in rapid acetylators; however, the falloff was fast in rapid acetylators, but was more gradual in slow acetylators. Coverage, defined as the number of hours for which a bacteriostatic concentration of isoniazid $(0.2 \mu \mathrm{g} / \mathrm{mL})$ is maintained in the blood, was significantly greater in slow acetylators. Similarly, exposure, defined as the area under the concentration-time curve, was significantly greater in slow acetylators. Significant differences in coverage and exposure between slow and rapid acetylators suggested that failure of once-weekly isoniazid regimens was because of suboptimal coverage and exposure among rapid acetylators. ${ }^{35}$

Weiner et al undertook a study to understand the reasons for lower efficacy of once-weekly isoniazid-rifapentine compared with twice-weekly isoniazid-rifampicin. This study showed that poor treatment outcomes were associated with isoniazid acetylator status in patients receiving a onceweekly regimen..$^{30}$

The isoniazid acetylator phenomenon could have important therapeutic implications in certain specific situations, such as during tuberculosis treatment in HIV-infected

Table I Prognostic significance of isoniazid acetylator status during once-weekly chemotherapy ${ }^{30}$

\begin{tabular}{lllllll}
\hline $\begin{array}{l}\text { Once-weekly } \\
\text { phase }\end{array}$ & \multicolumn{2}{l}{ Total patients } & & \multicolumn{3}{l}{$\begin{array}{l}\text { Favorable response at one } \\
\text { year }\end{array}$} \\
\cline { 2 - 3 } \cline { 5 - 6 } \cline { 5 - 7 } & Slow & Rapid & & Slow & Rapid & Difference \\
\hline SH & 38 & 39 & & $82 \%$ & $60 \%$ & $22 \%$ \\
SHZ & 67 & 34 & & $87 \%$ & $53 \%$ & $34 \%$ \\
SH & 109 & 67 & & $94 \%$ & $73 \%$ & $21 \%$ \\
SPH & 98 & 72 & & $95 \%$ & $76 \%$ & $19 \%$ \\
EH & 57 & 51 & & $91 \%$ & $57 \%$ & $34 \%$ \\
\hline
\end{tabular}

Abbreviations: $\mathrm{S}$, streptomycin; $\mathrm{H}$, isoniazid; $\mathrm{P}$, sodium para-aminosalicylic acid; E, ethambutol; Z, pyrazinamide. 
Table 2 Peak, coverage, and exposure following a dose of isoniazid $15 \mathrm{mg} / \mathrm{kg}$ body weight among patients with pulmonary tuberculosis $^{18}$

\begin{tabular}{llll}
\hline $\begin{array}{l}\text { Isoniazid } \\
\text { inactivation } \\
\text { rate }\end{array}$ & $\begin{array}{l}\text { Peak } \\
\text { concentration } \\
(\mu \mathrm{g} / \mathrm{mL})\end{array}$ & $\begin{array}{l}\text { Coverage } \\
(\mathbf{h})\end{array}$ & $\begin{array}{l}\text { Exposure } \\
(\mu \mathrm{g} / \mathbf{m L} \cdot \mathbf{h})\end{array}$ \\
\hline Slow & 13.8 & 30 & 85 \\
Rapid & 10.8 & 14 & 36 \\
\hline
\end{tabular}

individuals and in patients with chronic renal failure. A study undertaken by our group to understand the influence of HIV infection on the pharmacokinetics of antituberculous drugs, showed that differences in peak concentration and exposure of isoniazid between HIV-infected and HIV-noninfected patients with tuberculosis were more significant in rapid acetylators than in slow acetylators. Hence, among HIVinfected patients with tuberculosis, where bioavailability of antituberculous drugs has been shown to be suboptimal, rapid acetylators are at a further disadvantage. ${ }^{36,37}$

Determination of isoniazid acetylator status could be particularly important in patients with tuberculosis with chronic renal failure. The pharmacokinetics of isoniazid was compared between patients with chronic renal failure and healthy volunteers. While plasma isoniazid concentrations were similar in rapid acetylators and healthy subjects, peak isoniazid concentrations, exposure, and half-life were significantly higher in slow acetylators with renal failure than in healthy subjects $(P<0.01)$. This study suggested that it was necessary to reduce the dose of isoniazid in slow acetylators to reduce the incidence of adverse events. ${ }^{38}$

Donald et al studied the impact of isoniazid dose and NAT2 genotype and phenotype on the pharmacokinetics and pharmacodynamics of isoniazid in adult pulmonary patients with tuberculosis. This study showed that fast acetylators of isoniazid receiving a daily dose of $6 \mathrm{mg} / \mathrm{kg}$ had similar exposure to that of slow acetylators who received a daily dose of $3 \mathrm{mg} / \mathrm{kg}$. It was suggested that reducing the isoniazid dose below $6 \mathrm{mg} / \mathrm{kg}$ would be disadvantageous for fast acetylators, but $3 \mathrm{mg} / \mathrm{kg}$ was sufficient for slow acetylators to achieve optimal isoniazid exposure. ${ }^{39}$

In a population pharmacokinetic study of isoniazid in South African patients with tuberculosis by Wilkins et al, a model was developed to understand the pharmacokinetic variability of isoniazid. This study observed that the existing treatment guidelines could cause suboptimal exposure in rapid acetylators of isoniazid. ${ }^{40}$

A pharmacokinetic study by Jeena et al in children with tuberculosis suggested that isoniazid doses may have to be individualized based on age, acetylator status, and disease process. ${ }^{41}$ Other studies have also shown that decreased isoniazid exposure was likely to impact tuberculosis treatment outcomes in children who were rapid acetylators compared with slow acetylators. ${ }^{42-44}$ A recent pharmacokinetic study of antituberculous drugs undertaken in children at our center showed that isoniazid acetylator status significantly influenced drug levels and tuberculosis treatment outcome (unpublished data).

\section{Isoniazid-induced toxicity}

Isoniazid is quite nontoxic in conventional doses and is known to cause only two well recognized adverse reactions. Hepatotoxicity is the most common and serious adverse reaction that could occur during treatment of tuberculosis. The incidence of hepatotoxicity during antituberculous treatment is reported to vary from $2 \%$ to $28 \%{ }^{22}$ The other adverse event is peripheral neuropathy, which is common with high doses, particularly among slow acetylators. ${ }^{45}$ It is reversible and can be prevented by concomitant pyridoxine administration. ${ }^{46}$ These toxicities have been shown to be related to the slow clearance of acetyl hydrazine, a toxic metabolite of isoniazid in affected patients, who were identified as slow acetylators. ${ }^{19}$

Hepatotoxicity is a major toxic effect of isoniazid. This has caused concern because isoniazid is widely used in preventive therapy programs, apart from treating tuberculosis. Isoniazid undergoes metabolism by human enzymes to produce toxic chemicals that are likely to cause liver toxicity. Isoniazid-induced hepatotoxicity has been reported to be influenced by NAT2 acetylation, oxidation by cytochrome P450 oxidase (CYP) 2EI, and detoxification by glutathione S-transferase (GST, Figure 1). ${ }^{19}$

\section{NAT2 polymorphisms}

A few studies have attempted to establish the molecular and chemical basis for the occurrence of isoniazid-induced hepatotoxicity. Mitchell et al have proposed that the incidence of hepatotoxicity due to isoniazid could be greater in rapid acetylators than in slow acetylators. This is due to the fact that rapid acetylators produce monoacetyl hydrazine from isoniazid faster than slow acetylators; monoacetyl hydrazine subsequently gets converted by the CYP-dependent hepatic microsomal enzyme system to a potent acetylating agent which could cause hepatic necrosis. ${ }^{47}$ However, this hypothesis was questioned because of the fact that formation of monoacetyl hydrazine was similar in the two phenotypes, the more rapid formation for monoacetyl hydrazine being 
offset by its more rapid elimination via diacetyl hydrazine in rapid acetylators. ${ }^{48}$ Research reported by Sarma et al has shown that hydrazine formed from isoniazid is responsible for the hepatotoxic action of isoniazid metabolites. This reaction is modified by metabolic induction by rifampicin, which induces isoniazid metabolism by inducing isoniazid hydrolase, thereby producing isonicotinic acid and hydrazine. ${ }^{49}$ This direct pathway of isoniazid metabolism induced by rifampicin was shown to be more pronounced in slow acetylators than in rapid acetylators.

A 28-fold higher risk of isoniazid-induced hepatotoxicity in slow acetylators compared with rapid acetylators has been reported in Japanese and Taiwanese populations. ${ }^{50,51}$ Another study in a Korean population observed that slow NAT2 acetylators had a 3-8-fold risk of developing isoniazid-induced hepatotoxicity $(P=0.005)$. This study suggested that NAT2 genotyping could serve as a useful tool to predict antituberculous drug-induced hepatotoxicity. ${ }^{52}$ Slow acetylator status of NAT2 as a risk factor for isoniazid-induced hepatotoxicity was observed in a study conducted in Tunisian patients with tuberculosis, and the $N A T 2 * 53 / 5 B, N A T 2 * 6 A / 6 A, 481 T / T$, and $590 \mathrm{~A} / \mathrm{A}$ diplotypes could serve as useful biomarkers for prediction of antituberculous drug-induced toxicity. ${ }^{53}$ A retrospective study in 102 Japanese patients with tuberculosis showed that the occurrence of side effects was greater in slow acetylators than in rapid and intermediate acetylators. ${ }^{54}$ A recent meta-analysis by Wang et al of 14 studies, comprising 474 cases and 1446 controls, showed a significant association between slow NAT2 acetylators and risk of antituberculous drug-induced liver toxicity. ${ }^{55}$ The odds ratio (OR) for slow NAT2 acetylators compared with rapid acetylators was 4.7 (95\% confidence interval [CI] 3.3-6.7, $P<0.001)$. Subgroup analysis indicated that both Asian and non-Asian slow acetylators develop liver damage more frequently. On comparing intermediate NAT2 acetylators with rapid NAT2 acetylators, the OR was 1.3 (95\% CI 0.93-1.71, $P<0.14$ ). Another subgroup analysis for the different treatment regimens showed that the combined OR for isoniazid + rifampicin, isoniazid + rifampicin + pyrazinamide + ethambutol, and isoniazid were, respectively, 34.3 (95\% CI 10.4-113.0, $P<0.001)$, 4.1 (95\% CI 2.8-6.0, $P<0.001)$, and 2.4 (95\% CI $0.52-10.73, P<0.27$ ) on comparing slow NAT2 acetylators with rapid acetylators. Identifying genetic NAT2 polymorphisms in patients could help clinicians to prevent hepatotoxicity and achieve better patient management. ${ }^{55}$

Contrary to these findings, a case-control study undertaken in patients of Caucasian origin with tuberculosis did not find any association between increased risk of antituberculous drug-induced liver injury and the presence of slow NAT2 polymorphisms. ${ }^{56}$ Genotyping studies in an Indian population ${ }^{57}$ and in a heterogenous population consisting of Hispanics, Africans, Caucasians, South Americans, and Asians ${ }^{58}$ has reported a lack of association between isoniazid-induced hepatotoxicity and NAT2 acetylator status.

\section{CYP2EI polymorphisms}

CYP2E1 is one of the enzymes of the hepatic microsomal enzyme system, and brings about conversion of acetyl hydrazine to hepatotoxins, eg, acetyl diazene, ketene, and the acetylonium ion. ${ }^{59}$ It has been proposed that isoniazid or its metabolite, hydrazine, could induce $C Y P 2 E 1$ activity in the rat, and that this activity is driven by blood isoniazid levels. ${ }^{60}$ On the other hand, isoniazid could also inhibit the activity of $C Y P 2 E 1$, this being more prominent in individuals with the variant $C Y P 2 E 1$ genotype ${ }^{61}$ Hence, $C Y P 2 E 1$ activity is likely to be increased in individuals with a common genotype at CYP2E1 compared with those with the variant genotype. The risk of hepatotoxicity could increase due to enhanced CYP2E1 activity via increased production of hepatotoxins.

Lee et al have reported similar findings, and also observed that CYP2E1 was related to the severity of antituberculous drug-induced hepatotoxicity. ${ }^{62} \mathrm{~A}$ study from Taiwan showed that the common $* 1 A / * I A$ genotype of CYP2E1 enhanced the odds of isoniazid-induced liver toxicity by 2.5 times in adult patients with tuberculosis. ${ }^{61}$ Further, a combination of the $* 1 A / * 1 A$ genotype and slow NAT2 acetylation status increased the risk of hepatotoxicity (OR 7.43, 95\% CI 2.4-22.8) compared with the presence of any one polymorphism. Another study in Indian pediatric patients observed that the risk of liver toxicity was enhanced by the variant $C Y P 2 E 1 * 6$ allele and $* I A^{*} 6 * I D$ haplotype at $C Y P 2 E 1$ (OR 11.0, 95\% CI 1.02-11.0 and OR 4.6, 95\% CI 1.3-16.3, respectively). ${ }^{63}$ The common $* I A$ allele at $C Y P 2 E 1$ increasing the levels of liver enzymes was observed in a heterogenous group of Asians, Africans, Caucasians, South Americans, Hispanics, and Africans. ${ }^{56}$ However, a study done in a Korean population did not find an association between liver toxicity and CYP2E1 polymorphisms. ${ }^{52}$

\section{GSTMI and GSTTI polymorphisms}

The GSTs are a group of enzymes involved in the detoxification of carcinogens, toxic chemicals, and medications. ${ }^{64,65}$ GSTs bring about conjugation of glutathione with the substrate, for solubilization and elimination from the body. The GST enzymes are coded by at least five distinct loci. Of these, GSTM1 and GSTT1 are reported to be associated 
with hepatotoxicity. ${ }^{52,66}$ GSTs are reported to play a key role in the metabolism of isoniazid. Glutathione serves as a scavenger of free radicals intracellularly by conjugating with toxic metabolites of isoniazid. Inadequacy of GST activity due to homozygous deletion at GSTM1 and GSTT1 loci could influence susceptibility to isoniazid-induced liver toxicity. The risk of isoniazid-induced hepatotoxicity has been shown to be increased (OR 2.13, 95\% CI 1.25-3.10) in Indian patients with homozygous GSTM1 mutation. ${ }^{52}$ While Taiwanese patients with homozygous GSTM1 deletion were found to have twice the risk of isoniazid-induced hepatotoxicity in a Taiwanese population, this did not occur in those with homozygous GSTT1 deletion. ${ }^{52,66}$ Similar studies with reasonable sample sizes now have to be done in different ethnic populations. Identifying patients with homozygous GSTM1 deletion may help in the prevention and better management of isoniazid-induced hepatotoxicity.

\section{Manganese superoxide dismutase}

It is known that hepatic damage can be caused by reactive oxygen species formed from various reactions. Manganese superoxide dismutase brings about a decrease in the load of reactive oxygen species in the mitochondria. A study from Taiwan showed that genotypes with the variant $\mathrm{C}$ allele $(\mathrm{T}>\mathrm{C}$ polymorphism at codon 47 ; alanine $>$ valine) enhanced the risk of antituberculous drug-induced liver toxicity. ${ }^{66}$ This is probably because manganese superoxide dismutase with the variant amino acid, valine, at codon 47 augmented formation of toxic hydrogen peroxide, which can lead to hepatotoxicity.

\section{Human leucocyte antigen alleles}

The lack of HLADQA $1 * 0102$ and existence of DQB $1 * 0201$ alleles have been reported to be independently associated with an enhanced risk of antituberculous-induced hepatotoxicity in Indian patients. ${ }^{67}$

\section{Rifampicin}

Rifampicin is an important first-line drug used to treat tuberculosis. It has shown concentration-dependent activity against M. tuberculosis under in vitro and in vivo conditions. ${ }^{68-70}$ Organic anion transporter peptides play an important role in the transport and disposition of drugs in the human body. Rifampicin is a substrate of drug transporters such as P-glycoprotein and OATP1B1. Nuclear receptors, ie, pregnane X receptor and constitutive androstane receptor, transcriptionally regulate the drug transporters. Weiner et al undertook a pharmacokinetic study to explore the reasons for the huge interindividual variations in rifampicin levels seen in patients receiving standard treatment dosages. The pharmacokinetics of rifampicin was compared between patients with tuberculosis and healthy subjects, between regions (Africa versus non-Africa), and between races (black versus other races). The relationship between rifampicin pharmacokinetics and polymorphisms of drug influx and efflux transporter genes (anion transporting polypeptides [SLCO1B1 463C $>\mathrm{A}$ and $521 \mathrm{~T}>\mathrm{C}$ and SLCO1B3] and P-glycoprotein [ABCBI]) was also studied.$^{20}$ The study findings in 72 adult pulmonary patients with tuberculosis from the US, Africa, and Spain showed that polymorphisms in the SLCO1B1 gene had a significant influence on rifampicin exposure, this being $36 \%$ lower among SLCO1B1 463 CA genotypes than CC genotypes (29.8 versus $46.7 \mu \mathrm{g} \cdot \mathrm{h} / \mathrm{mL} ; P=0.001$, Figure 4).$^{20}$ Further, $S L C O 1 B 1$ gene polymorphisms related to reduced rifampicin exposure were more pronounced in black subjects. This study was the first to report an association between rifampicin exposure and SLCO1B1 $463 \mathrm{C}>\mathrm{A}$ gene polymorphism. Marked interindividual variations in rifampicin exposure were probably due to this polymorphism.

Chigutsa et al undertook a study in South African patients with tuberculosis to examine the impact of $A B C B 1$, SLCO1B1, PXR, and CAR polymorphisms on the pharmacokinetics of rifampicin. ${ }^{21}$ Patients heterozygous and homozygous for the variant allele of SLCO1B1 rs 4149032 polymorphism had decreases in rifampicin bioavailability of $20 \%$ and $28 \%$, respectively. This polymorphism explained $21 \%$ of the between-subject variability in drug clearance.

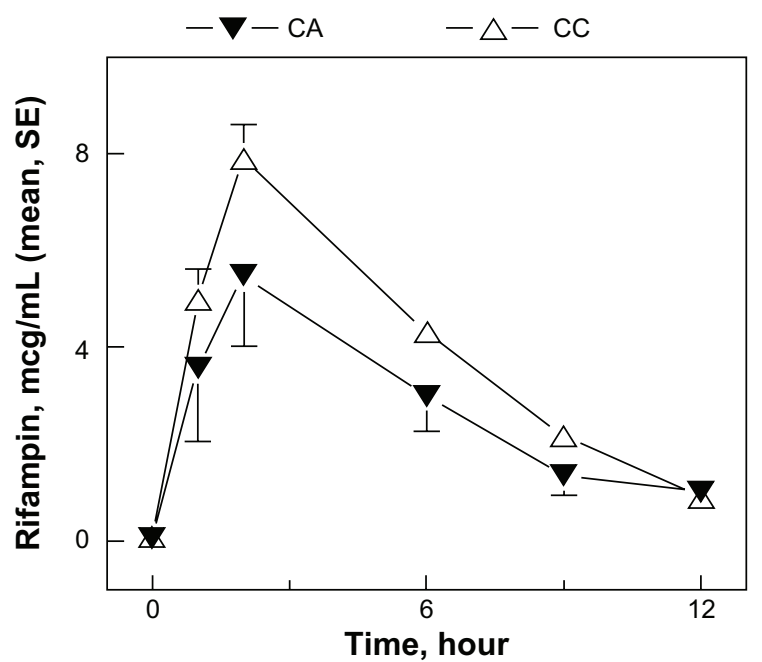

Figure 4 Plasma rifampin concentrations ( $\mu \mathrm{g} / \mathrm{mL}$ ) versus time (hours) in patients grouped by SLCOIBI c.463CA polymorphisms $(\boldsymbol{\nabla})$ versus SLCOIBI c.463CC genotypes $(\Delta)$. (C) Copyright American Society for Microbiology. Reprinted with permission from Weiner M, Peloquin CA, Burman W, et al. Effects of tuberculosis, race, and human gene SLCOIBI polymorphisms on rifampin concentrations. Antimicrob Agents Chemother. 2010;54(I0):4192-4200. ${ }^{20}$

Note: Arithmetic mean and standard error shown with vertical bars. 
Simulations revealed that an increase in rifampicin dose of approximately $30 \%$ in patients harboring the polymorphism resulted in plasma rifampicin levels similar to those for the wild-type allele, with a typical peak concentration above the recommended minimum of $8 \mu \mathrm{g} / \mathrm{mL}$. However, the other polymorphisms, ie, for $A B C B 1, P X R$, and $C A R$, did not have any significant impact on the pharmacokinetics of rifampicin. This study suggests that an increase in rifampicin dose would be desirable for carriers of the $S L C O B 1 B 1$ polymorphism. More studies in different populations are required to understand the role of $S L C O B 1 B 1$ polymorphisms in influencing plasma rifampicin concentrations and their role in impacting tuberculosis treatment outcomes.

\section{Aminoglycosides}

Aminoglycosides, such as streptomycin, kanamycin, and amikacin, are used in the treatment of tuberculosis. Ototoxicity is an adverse event that can arise following the use of aminoglycosides. Zhao et al undertook a molecular characterization study in a Chinese family to understand the association between aminoglycoside-induced ototoxicity and mitochondrial mutations. It was observed that a $\mathrm{C}$ to $\mathrm{T}$ transition at position 1494 in the mitochondrial 12S rRNA gene was responsible in individuals genetically predisposed to ototoxicity. ${ }^{71}$ It was likely that the deafness phenotype linked to the $\mathrm{C}>\mathrm{T} 1494$ 12S rRNA gene polymorphism could be induced or worsened by aminoglycosides.

\section{Translating pharmacogenomics to the clinic}

Although genetic polymorphisms are known to impact drug effects, individualized drug therapy is seldom used in clinical practice. This could be because it is difficult to carry out well designed clinical pharmacogenomic studies to prove that individualization of drug treatment on a genetic basis helps in improving clinical outcomes. The multigenic nature of most drug effects and practical problems in controlling for nongenetic confounders, eg, drug interactions, diet, and smoking, are some of the limitations in conducting such studies. Prospective clinical trials on a large scale are necessary to quantitate drug response objectively. In order to achieve this, it is important to obtain genomic DNA from all patients recruited into clinical trials, and obtain consent to carry out pharmacogenetic studies. It would be ideal to couple these trials with preclinical experimental models that reinforce clinical associations between genotypes and phenotypes. Inclusion of pharmacogenetic testing in clinical trials is necessary for clinical progress. Because of marked population heterogeneity, there is a need to validate pharmacogenomic relationships for every therapeutic indication and in various ethnic/racial groups. This would help in reducing the occurrence of adverse drug effects and enhancing treatment success, and in the long run will probably decrease the cost of health care. Pharmacogenomic studies have the potential to achieve this by translating genome variability into improved therapeutics.

\section{Conclusion}

Among the antituberculous drugs, isoniazid metabolism and disposition is known to be impacted by genetic factors. The relationship between ethnicity, genetic background, and response to tuberculosis treatment has not been well studied. It has been reported that no single gene variant of NAT2 or CYP2E1 is significantly associated with isoniaziddriven hepatotoxicity. ${ }^{72}$ Thus, a combination of polymorphisms could impact the pharmacokinetics of isoniazid. For most antituberculous drugs, both efficacy and toxicity are most likely determined by multiple factors, with both genetic and non-genetic factors playing a role. Large clinical trials will be needed to evaluate prospectively the merits of using genotyping and adjustment of tuberculosis drug doses during treatment. More studies are also required to understand the influence of $S L C O 1 B 1$ gene polymorphism on rifampicin pharmacokinetics, as well as polymorphisms affecting the metabolism of other first-line and second-line antituberculous drugs. These studies must link pharmacogenetic data with tuberculosis treatment outcomes. Ultimately, we also have to bear in mind the cost, cost-effectiveness, and feasibility of using pharmacogenomics in routine tuberculosis control programs. Unless the benefits of genetic testing and individualizing treatment are worth the cost of such an exercise, the approach will not find many takers, because tuberculosis is mainly a disease of poverty.

\section{Acknowledgment}

The authors thank Aleyamma Thomas of the National Institute for Research in Tuberculosis, Chennai, India, for her encouragement and support of this work.

\section{Disclosure}

The authors report no conflicts of interest in this work.

\section{References}

1. World Health Organisation. Global TB report, 2010.

2. Crofton J. Global challenge of TB. Lancet. 1994;344(8922):609.

3. Menzies D, Benedetti A, Payder A, et al. Effect of duration and intermittency of rifampin on TB treatment outcomes: a systematic review and meta-analysis. PLoS Med. 2009;6(9):e1000146. 
4. Vesell ES. Pharmacokinetic perspectives gained from twin and family studies. Pharmacol Ther. 1989;41(3):535-552.

5. Kalow W, Thang BK, Endreyi L. Hypothesis: comparisons of inter and intra-individual variations can substitute for twin studies in drug research. Pharmacokinetics. 1998;8(4):283-289.

6. Evans WE, Relling MV. Pharmacogenomics: translating functional genomics into rational therapeutics. Science. 1999;286(5439):487-491.

7. Evans WE, Johnson JA. Pharmacogenomics: the inherited basis for inter individual differences in drug response. Annu Rev Genomics Hum Genet. 2001;2:9-39.

8. McLeod HL, Evans WE. Pharmacogenomics: unlocking the human genome for better drug therapy. Annu Rev Pharmacol Toxicol. 2001;41: $101-121$.

9. Lehmann H, Ryan E. Familial incidence of low pseudo cholinesterase level. Lancet. 1956;271(6934):124.

10. Alving AS, Carson PE, Flanagan CL et al. Enzymatic deficiency in primaquine-sensitive erythrocytes. Science. 1956;124(3220): 484-485.

11. Hughes HB, Biehl JP, Jones AP, Schmidt LH. Metabolism of isoniazid in man as related to the occurrence of peripheral neuritis. Am Rev Tuberc. 1954;70(2):266-273.

12. Evans DA, Manley KA, McKusick VA. Genetic control of isoniazid metabolism in man. Br Med J. 1960;2(5197):485-491.

13. Sachidanandam R, Weissman D, Schmidt SC, et al. A map of human genome sequence variation containing 1.42 million single nucleotide polymorphisms. Nature. 2001;409(6822):928-933.

14. Evans WE, Relling MV. Moving towards individualized medicine with pharmacogenomics. Nature. 2004;429(6990):464-468.

15. Evans WE. Pharmacogenomics: marshalling the human genome to individualise drug therapy. Gut. 2003;52 Suppl II:ii10-ii18.

16. [No authors listed]. Pharmacogenomics. Available at: http:// en.wikipedia.org/wiki/pharmacogenomics. Accessed August 7, 2012

17. Ellard GA, Gammon PT. Pharmacokinetics of isoniazid metabolism in man. J Pharmacokinet Biopharm. 1976;4(2):83-113.

18. Raghupati Sarma G. Isoniazid metabolism in man and its therapeutic implications. Proceedings of the Symposium on Clinical Pharmacokinetics. 1978.

19. Roy PD, Majumder M, Roy B. Pharmacogenomics of anti-TB drug-related hepatotoxicity. Pharmacogenomics. 2008;9(3):311-321.

20. Weiner M, Peloquin CA, Burman W, et al. Effects of tuberculosis, race, and human gene $S L C O 1 B 1$ polymorphisms on rifampin concentrations. Antimicrob Agents Chemother. 2010;54(10):4192-4200.

21. Chigutsa E, Visser ME, Swart EC, et al. The SLCO1B1 rs4149032 polymorphism is highly prevalent in South Africans and is associated with reduced rifampin concentrations: dosing implications. Antimicrob Agents Chemother. 2011;55(9):4122-4127.

22. Tostmann A, Boeree MJ, Aarnoutse et al. Antituberculosis drug-induced hepatotoxicity: concise up-to-date review. $J$ Gasteroenterol Hepatol. 2008;23(2):192-202.

23. Biomedical Research and Training Institute. Pharmacogenetics and drugdrug interactions in the treatment of tuberculosis - potential clinical implications in Zimbabwe. Oct 2011. Available from: http://www.brti.co.zw.

24. Cascorbi L, Roots I. Pitfalls in N-acetyl transferase 2 genotyping. Pharmacogenetics. 1999;9(1):123-127.

25. Kinzig-Schippers M, Tomalik-Scharte D, Jetter A, et al. Should we use $\mathrm{N}$-acetyl transferase type 2 genotyping to personalize isoniazid doses? Antimicrob Agents Chemother. 2005;49(5):1733-1738.

26. Parkin DP, Vandenplas S, Botha FJ, et al. Trimodality of isoniazid elimination: phenotype and genotype in patients with tuberculosis. $\mathrm{Am}$ J Respir Crit Care Med. 1997;155(5):1717-1722.

27. Kita T, Tanigawara $\mathrm{Y}$, Chikazawa $\mathrm{S}$, et al. N-acetyl transferase-2 genotype correlated with isoniazid acetylation in Japanese tuberculous patients. Biol Pharm Bull. 2001;24(5):544-549.

28. Mitchison DA. Drug resistance in mycobacteria. Br Med Bull. 1984; 40(1):84-90.

29. Donald PR, Sirgel FA, Botha FJ, et al. The influence of human N-acetyl transferase genotype on the early bactericidal activity of isoniazid. Clin Infect Dis. 2004;39(10):1425-1430.
30. Weiner M, Burman W, Vernon A, et al. Low isoniazid concentrations and outcome of tuberculosis treatment with once weekly isoniazid and rifapentine. Am J Respir Crit Care Med. 2003;167(10):1341-1347.

31. Selkon JB, Fox W, Gangadharam PRJ, et al. Rate of inactivation of isoniazid in south Indian patients with pulmonary tuberculosis-2. Clinical implications in the treatment of pulmonary tuberculosis with isoniazid either alone or in combination with PAS. Bull World Health Organ. 1961;25:779-792.

32. [No authors listed]. Controlled comparison of oral twice-weekly and oral daily isoniazid plus PAS in newly diagnosed pulmonary tuberculosis. Br Med J. 1973;2(5857):7-11.

33. [No authors listed]. Controlled comparison of oral twice-weekly and three once weekly regimens in the initial treatment of pulmonary tuberculosis. Bull World Health Organ. 1970;43(1):143-206.

34. [No authors listed]. Controlled comparison of two fully supervised once weekly regimens in the treatment of newly diagnosed pulmonary tuberculosis. Tubercle. 1973;54(1):23-45.

35. Sarma GR, Kailasam S, Mitchison DA, et al. Studies of serial plasma isoniazid concentrations with different doses of a slow release preparation of isoniazid. Tubercle. 1975;56(4):314-323.

36. Gurumurthy P, Ramachandran G, Hemanth Kumar AK, et al. Decreased bioavailability of rifampin and other anti-TB drugs in patients with advanced HIV disease. Antimicrob Agents Chemother. 2004;48(11): 4473-4475.

37. Ramachandran G, Hemanth Kumar AK, Rajasekaran S, et al. Acetylator status influences bioavailability of isoniazid in patients with advanced HIV disease. SAARC J Tuberc Lung Dis HIV/AIDS. 2005;II(2):9-12.

38. Gurumurthy P, Raghupati Sarma G, Jayasankar K, et al. Single-dose pharmacokinetics of isoniazid and rifampicin in patients with chronic renal failure. Ind J Tub. 1992;39:221-228.

39. Donald PR, Parkin DP, Seifart HI, et al. The influence of dose and $\mathrm{N}$-acetyl transferase-2 (NAT2) genotype and phenotype on the pharmacokinetics and pharmacodynamics of isoniazid. Pharmacokinet Dispos. 2007;63(7):633-639.

40. Wilkins JJ, Langdon G, McIlleron H, et al. Variability in the population pharmacokinetics of isoniazid in South African tuberculosis patients. Br J Clin Pharmacol. 2011;72(1): 51-62.

41. Jeena PM, Bishai WR, Pasipanodya JG, Gumbo T. In silico children and the glass mouse model; clinical trial simulations to identify and individualize optimal isoniazid doses in children with tuberculosis. Antimicrob Agents Chemother. 2011;55(2):539-545.

42. McIlleron H, Willemse M, Werely CJ, et al. Isoniazid plasma concentrations in a cohort of south African children with tuberculosis: implications for international pediatrics dosing guidelines. Clin Infect Dis. 2009;48(11):1547-1553.

43. Cranswick N, Mulholland K. Isoniazid treatment of children: can genetics help guide treatment? Arch Dis Child. 2005;90(6):551-553.

44. Schaaf HS, Parkin DP, Seifart HI, et al. Isoniazid pharmacokinetics in children treated for respiratory tuberculosis. Arch Dis Child. 2005; 90(6):614-618.

45. Devadatta S, Gangadharam PRJ, Andrews RH, et al. Peripheral neuritis due to isoniazid. Bull World Health Organ. 1960;23:587-598.

46. No authors listed. The prevention and treatment of isoniazid toxicity in the therapy of pulmonary tuberculosis 2 . An assessment of the prophylactic effect of pyridoxine in low dosage. Bull World Health Organ. 1963;29: 457-481.

47. Mitchell JR, Zimmerman HJ, Ishak KG, et al. Isoniazid liver injury: clinical spectrum, pathology and probable pathogenesis. Ann Intern Med. 1976;84(2):181-192.

48. Ellard GA. Slow release preparation of isoniazid: pharmacological aspects. Bull Int Union Tuberc. 1976;51(1):143-154.

49. Sarma GR, Immanuel C, Kailasam S, et al. Rifampin induced release of hydrazine from isoniazid: a possible cause of hepatitis during treatment of tuberculosis with regimens containing isoniazid and rifampin. Am Rev Respir Dis. 1986;133(6):1072-1075.

50. Ohno M, Yamaguchi I, Yamamoto I, et al. Slow N-acetyltransferase 2 genotype affects the incidence of isoniazid and rifampicin induced hepatotoxicity. Int J Tuberc Lung Dis. 2000;4(3):256-261. 
51. Huang YS, Chern HD, Su WJ, et al. Polymorphisms of N-acetyl transferase 2 gene as susceptibility risk factors for anti-tuberculosis drug induced hepatitis. Hepatology. 2002;35(4):883-889.

52. Cho HJ, Koh WJ, Ryu YJ, et al. Genetic polymorphisms of NAT2 and CYP2E1 associated with anti tuberculosis drug-induced hepatotoxicity in Korean patients with pulmonary tuberculosis. Tuberculosis (Edinb). 2007;87(6):551-556.

53. Mahmoud BL, Ghozzi H, Kamoun A, et al. Polymorphism of the $\mathrm{N}$-acetyltransferase 2 gene as a susceptibility risk factor for antituberculosis drug-induced hepatotoxicity in Tunisian patients with tuberculosis. Pathol Biol (Paris). Aug 2011. [Epub ahead of print.]

54. Hiratsuka MY, Kushikawa Y, Takekuma M, et al. Genotyping of the $\mathrm{N}$-acetyltransferase polymorphism in the prediction of adverse reactions to isoniazid in Japanese patients. Drug Metab Pharmacokinet. 2002; 17(4):357-362.

55. Wang PY, Xie SY, Hao Q, Xiang BF. NAT2 polymorphisms and susceptibility to anti-tuberculosis drug-induced liver injury: meta-analysis. Int J Tuberc Lung Dis. 2012;16(5):589-595.

56. Leiro-Fernandez V, Valverde D, Vazques-Gallardo R, et al. N-acetyl transferase 2 polymorphisms and risk of anti-tuberculosis drug-induced hepatotoxicity in Caucasians. Int J Tuberc Lung Dis. 2011;15(10): 1403-1408.

57. Roy B, Chowdhury A, Kundu S, et al. Increased risk of anti-tuberculosis drug-induced hepatotoxicity in individuals with glutathione S-transferase M1 null mutation. J Gastroenterol Hepatol. 2001;16(9):1033-1037.

58. Vuilleumier N, Rossier MF, Chiappe A, et al. CYP2E1 genotype and isoniazid induced hepatotoxicity in patients treated for latent tuberculosis. Eur J Clin Pharmacol. 2006;62(6):423-429.

59. Nelson SD, Mitchell JR, Timbrell JA, Snodgrass WR, Corcoran GB 3rd. Isoniazid and iproniazid: activation of metabolites to toxic intermediates in man and rat. Science. 1976;193(4256):901-903.

60. Yue J, Peng RX, Yang J, Kong R, Liu J. CYP2E1 mediated isoniazid induced hepatotoxicity in rats. Acta Pharmacol Sin. 2004;25(5): 699-704.

61. Huang YS, Chern HD, Su WJ, et al. Cytochrome P450 2 E1 genotype and the susceptibility to anti tuberculosis drug induced hepatitis. Hepatology. 2003;37(4):924-930.

62. Lee SW, Chung LS, Huang HH, et al. NAT2 and CYP2E1 polymorphisms and susceptibility to first-line anti-tuberculosis drug-induced hepatitis. Int J Tuberc Lung Dis. 2010; 14(5):622-626.
63. Roy B, Ghosh SK, Sutradhar D, et al. Predisposition of anti-tuberculosis drug induced hepatotoxicity by cytochrome P450 2E1 genotype and haplotype in pediatrics patients. $J$ Gastroenterol Hepatol. 2006;21(4):781-786.

64. Strange RC, Jones PW, Fryer AA. Glutathione S-transferase: genetics and role in toxicology. Toxicol Lett. 2000;112-113:357-363.

65. Simon T, Becquemont L, Mary-Krause M, et al. Combined glutathione S-transferase M1 and T1 genetic polymorphism and tacrine hepatotoxicity. Clin Pharmacol Ther. 2000;67(4):432-437.

66. Huang YS, Su WJ, Huang YH, et al. Genetic polymorphisms of managanese superoxide dismutase, $\mathrm{NAD}(\mathrm{P}) \mathrm{H}$ : quinone oxidoreductase, glutathione S-transferase M1 and T1 and the susceptibility to drug induced liver injury. J Hepatol. 2007;47(1):128-134.

67. Sharma SK, Balamurugan A, Saha PK, et al. Evaluation of clinical and immunogenetic risk factors for the development of hepatotoxicity during anti-tuberculosis treatment. Am J Respir Crit Care Med. 2002;166(7):916-919.

68. Grosset JH, Rosenthal IM, Zhang M, et al. Dose ranging comparison of rifampin and rifapentine in combination with isoniazid and pyrazinamide in the mouse model of tuberculosis. Abstract A-1825 presented at the 46th Annual Meeting of American Society for Microbiology and Infectious Diseases Society of America, October 25-28, 2008, Washington DC.

69. Jayaram R, Gaonkar S, Kaur P, et al. Pharmacokinetics and pharmacodynamics of rifampin in an aerosol infection model of tuberculosis. Antimicrob Agents Chemother. 2003;47(7):2118-2124.

70. Ji B, Truffot Pernot C, Lacroix C, et al. Effectiveness of rifampin, rifabutin and rifapentine for preventive therapy of tuberculosis in mice. Am Rev Respir Dis. 1993;148(6 Pt 1):1541-1546.

71. Zhao H, Li R, Wang Q, et al. Maternally inherited aminoglycosideinduced and nonsyndromic deafness is associated with the novel C1494T mutation in the mitochondrial 12S rRNA gene in a large Chinese family. Am J Hum Genet. 2004;74(1):139-152.

72. Yamada S, Tang M, Richardson $K$, et al. Genetic variations of NAT2 and CYP2E1 and isoniazid hepatotoxicity in a diverse population. Pharmacogenomics. 2009;10(9):1433-1445.
Pharmacogenomics and Personalized Medicine

\section{Publish your work in this journal}

Pharmacogenomics and Personalized Medicine is an international, peerreviewed, open access journal characterizing the influence of genotype on pharmacology leading to the development of personalized treatment programs and individualized drug selection for improved safety, efficacy and sustainability. This journal is indexed on the American Chemical

\section{Dovepress}

Society's Chemical Abstracts Service (CAS). The manuscript management system is completely online and includes a very quick and fair peer-review system, which is all easy to use. Visit http://www.dovepress. com/testimonials.php to read real quotes from published authors. 